\title{
THE EFFECT OF $\mathrm{PCO}_{2}$ ON HYPOXIC PULMONARY VASOCONSTRICTION
}

\author{
William H. Noble, J. Colin Kay and Joseph A. Fisher
}

\begin{abstract}
Lung areas with a low $V / Q$ ratio cause hypoxaemia. The low alveolar oxygen concentration may cause local hypoxic pulmonary vasoconstriction (HPV) which reduces perfusion, raises the $\mathrm{V} / \mathrm{Q}$ ratio, and hence reduces the tendency to a low $\mathrm{Pa}_{\mathrm{O}_{2}}$. By changing $\mathrm{PCO}_{2}$, the HPV response can be altered. We examined this relationship in anaesthetized dogs by using a tracheal divider to separate hypoxic (nitrogen ventilated) from oxygenated (100 per cent oxygen ventilated) lung. Relative perfusion was assessed from total ${ }^{133} \mathrm{Xe}$ exhaled from each lung area after intravenous infusions. When $\mathrm{Pa}_{\mathrm{CO}_{2}}$ was changed by changing ventilation, we found that an increasing $\mathrm{Pa}_{\mathrm{CO}_{2}}$ increased $\mathrm{HPV}$ and also $\mathrm{Pa}_{\mathrm{O}_{2}}$. At a $\mathrm{Pa}_{\mathrm{CO}_{2}}$ of $3.3 \mathrm{kPa}, \mathrm{HPV}$ was abolished and $\mathrm{Pa}_{\mathrm{O}_{2}}$ fell. We also changed $\mathrm{Pa}_{\mathrm{CO}_{2}}$ by altering $\mathrm{PI}_{\mathrm{CO}_{2}}$ to one or both lung areas while ventilation remained constant throughout the experiment. Again as $\mathrm{Pa}_{\mathrm{CO}_{2}}$ increased, $\mathrm{HPV}$ and $\mathrm{Pa}_{\mathrm{O}_{2}}$ increased. When $\mathrm{Pa}_{\mathrm{CO}_{2}}$ fell and end tidal carbon dioxide in the hypoxic lung ( $\mathrm{PET}_{\mathrm{CO}_{2}}$ ) remained eleyated (by maintaining $\mathrm{PI}_{\mathrm{CO}_{2}}$ in the hypoxic lung and removing $\mathrm{CO}_{2}$ from the oxygenated lung) HPV was maintained. Thus it is the alveolar concentration of $\mathrm{CO}_{2}$ in the hypoxic lung which is important in modifying HPV.

We conclude that in this model a low $\mathrm{PET}_{\mathrm{CO}_{2}}(3.3 \mathrm{kPa})$ in hypoxic lung will reduce $\mathrm{HPV}$, and will result in more severe hypoxaemia. This may have relevance in both anaesthetized and intensive care unit patients when a higher $\mathrm{Pa}_{\mathrm{O}_{2}}$ may be obtained by increasing hypoxic lung $\mathrm{PET}_{\mathrm{CO}_{2}}$. The effect of $\mathrm{PET}_{\mathrm{CO}_{2}}$ on $\mathrm{Pa}_{\mathrm{O}_{2}}$ will be influenced by other variables, but when hypoventilated or hypoxic lung areas exist, increasing $\mathrm{PET}_{\mathrm{CO}_{2}}$ may reinforce hypoxic pulmonary vasoconstriction and thus may increase $\mathrm{Pa}_{\mathrm{O}_{2}}$.
\end{abstract}

KEY WORDS: LUNG, hypoxic vasoconstriction, carbon dioxide.

RESPIRATORY GAS EXCHANGE depends on the ratio of ventilation to perfusion. A low $V / Q$ ratio and hypoxaemia will result from poorly ventilated lung unless perfusion is also reduced in the same region. Alveolar oxygen concentration helps to match regional perfusion to ventilation through a mechanism of hypoxic pulmonary vasoconstriction (HPV). ${ }^{1-3}$

The mechanism of HPV is still not understood, but several events which occur under anaesthesia are reported to reduce HPV (and therefore to create hypoxaemia). Sykes, et al.,$^{4-7}$ Benumof and Wahrenbrock, ${ }^{8}$ and Bjertnaes ${ }^{9,10}$ have found that inhaled anaesthetics reduce HPV. Benumof, et al." have found that increased pulmonary vascular pressure can reduce $\mathrm{HPV} . \mathrm{PCO}_{2}$ is also known to affect HPV. ${ }^{1-13}$

$\mathrm{PCO}_{2}$ during anaesthesia may be increased, decreased, or normal. If HPV were present and a low $\mathrm{PCO}_{2}$ reduced $\mathrm{HPV}$, the low $\mathrm{PCO}_{2}$ could create hypoxaemia by increasing perfusion to hypoxic lung. $\mathrm{PCO}_{2}$ may also alter $\mathrm{Pa}_{\mathrm{O}_{2}}$ through its

William H. Noble, M.D., F.R.C.P.(C); J. Colin Kay, A.I.M.L.T.: Joseph A. Fisher, M.D., F.R.C.P.(C); Department of Anaesthesia, University of Toronto, St. Michael's Hospital, 30 Bond Street, Toronto, Ontario, M5B IW8.

Canad. Anaesth. Soc. J., vol. 28, no. 5, September 198 effect in the alveolar gas equation or by changing the position of the oxyhaemoglobin dissociation curve, cardiac output, or $\mathrm{R}$ values. In order to document which effect was dominant we assessed HPV in dogs and observed the effect of altering ventilation and therefore $\mathrm{Pa}_{\mathrm{CO}_{2}}$ on both HPV and $\mathrm{Pa}_{\mathrm{O}_{2}}$ when one third of the lung was made hypoxic. The relative importance of end tidal and arterial $\mathrm{PCO}_{2}$ changes on HPV were also investigated by altering inspired carbon dioxide to two separate lung areas (one hypoxic, the other oxygenated) while ventilation was unchanged.

\section{Methods}

The experiments were carried out on 38 mongrel dogs weighing $25-30 \mathrm{~kg}$. The animals were anaesthetized with pentobarbitone $30 \mathrm{mg} \cdot \mathrm{kg}^{-1}$ intravenously. Anaesthesia was maintained with intermittent infusions of pentobarbitone and pancurium bromide, as these agents have been shown not to affect HPV. ${ }^{10}$ The dogs were intubated through a tracheostomy with a Carlens double lumen tracheal tube, to separate two lung areas. It was important that the lung separation remain constant throughout the experiment. To 
be assured of this: (a) the inflated cuff seal was checked for leaks by ventilating the animal through one lumen while the other was attached to a tube submerged under water; (b) $\mathrm{PI}_{\mathrm{O}_{2}}$ was measured by testing gas aspirated from each bronchus during inspiration when nitrogen was in one lung and oxygen in the other; and (c) the ratio of ventilation to the two lung areas was monitored throughout the experiment. If this ratio changed, as it occasionally did due to tube movement or cuff leakage, the results were discarded.

Each limb of the Carlens tube was connected to a secondary ventilator circuit, modified from Sykes, ${ }^{14}$ which allowed the lungs to be synchronously but independently ventilated to the same pressure with separate gases (see Figure 1 for explanation of mechanism). With this system the gas distribution to the lungs depends on the compliance of the lung to which it is attached and expired gas can be collected separately from each lung area to measure ventilation. In order to maintain oxygenation when nitrogen was used, nitrogen was always ventilated into the smaller lung area and the other lung was ventilated with 100 per cent oxygen. Inspired and end tidal $\mathrm{Po}_{2}$ and $\mathrm{PCO}_{2}$ from each lung were measured intermittently by aspirating gas from a $1.7 \mathrm{~mm}$ O.D. catheter situated in the bronchi through the Carlens tube.

To measure the distribution of blood flow to each lung area we used a technique described by Arborelius. ${ }^{15}{ }^{133} \mathrm{Xe}$ was dissolved in saline and $1 \mathrm{mc}$ was infused rapidly into a central vein. Because of its low solubility ${ }^{133} \mathrm{Xe}$ diffuses into alveolar gas, and is washed out by ventilation. Immediately following the injection, expired gas from each lung was collected for seven minutes and the volume was measured. A $10 \mathrm{ml}$ sample of mixed expired gas collected from each lung was counted in a scintillation counter to give ${ }^{133} \mathrm{Xe}$ $\mathrm{cpm} / \mathrm{ml}$. The ${ }^{133} \mathrm{Xe}$ excreted by each lung area is proportional to its perfusion. Then ${ }^{133} \mathrm{Xe}$ excreted by the hypoxic lung divided by the total ${ }^{133} \mathrm{Xe}$ excreted indicates the proportion of perfusion to the hypoxic lung. The model thus compares the perfusion between any two ventilated lung areas isolated by the insertion of the Carlen's double lumen tube. In our experiments ventilation between the two lung areas remained constant, eliminating its contribution as a source of error.

The pulmonary artery, femoral artery and femoral vein were catheterized to monitor pressures continuously with pressure transducers.

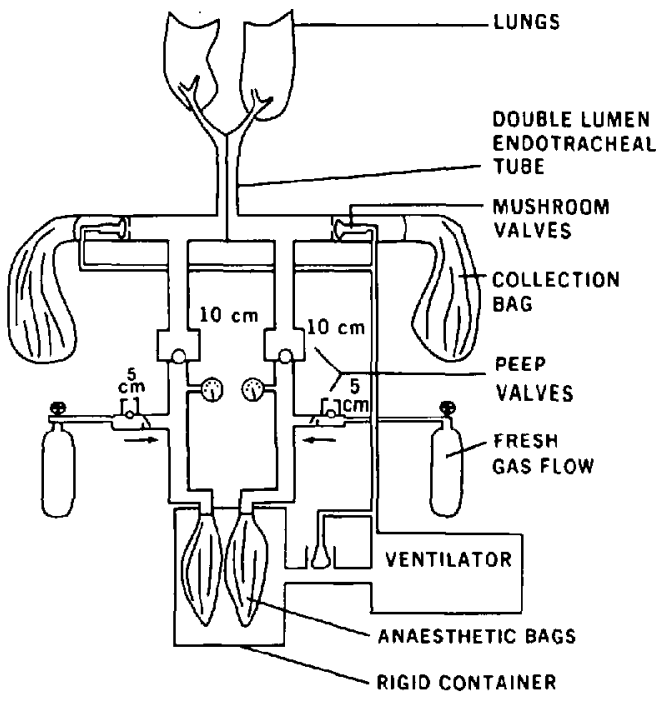

Figure I Secondary ventilator circuit used to separate inspired and expired gases in each lung. During expiration, a known gas fills two anaesthetic bags within a rigid container. The $10 \mathrm{~cm} \mathrm{H}_{2} \mathrm{O}$ PEEP valve remains closed while the bags fill. When the bags are full the rise in pressure closes one way valves, resulting in venting of excess fresh gases. During the inspiratory cycle the volume cycled ventilator (OHIO 560) forces a volume of gas into the rigid container, opening the 10 $\mathrm{cm} \mathrm{H}_{2} \mathrm{O}$ PEEP valve and displacing the same volume from the bags into the lungs. The distribution of gas to the lungs depends on the compliance of the lung to which it is attached. A non-rebreathing mushroom valve synchronized with the primary ventilator circuit prevents contamination of expired gas with inspired gas.

All lines were kept patent by intermittent flushing with physiological saline, and no heparin was used. Arterial and mixed venous blood samples were obtained for blood gas analysis, and cardiac output was determined using the thermodilution principle. ${ }^{16}$

\section{Experimental Protocol}

There were two groups of dogs. In the $\Delta$ VENTILATION group, measurements were taken at a specific $\mathrm{Pa}_{\mathrm{CO}_{2}}$ and with each lung area ventilated with 100 per cent oxygen to remove all HPV. At the same $\mathrm{Pa}_{\mathrm{CO}_{2}}$ we then introduced nitrogen into the smaller lung area to create HPV and repeated the measurements. With one lung ventilated with nitrogen and the other with oxygen, $\mathrm{Pa}_{\mathrm{CO}_{2}}$ was increased or decreased by changing ventilation. Haemodynamic and respiratory measurements were repeated after $\mathrm{PET}_{\mathrm{Co}_{2}}$ had stabilized (usually between 30 and 90 minutes).

In the inspired carbon dioxide group, $\mathrm{Pa}_{\mathrm{CO}_{2}}$ was 
altered by adding or removing inspired carbon dioxide to one or both lung areas while ventilation stayed constant throughout the experiment. Again, measurements were taken when haemodynamic and respiratory variables had stabilized (30 to 90 minutes).

Results are expressed as mean \pm S.E.M. Differences were assessed using unpaired and paired Student's ' $t$ ' test. Regression equations and correlations were determined using the method of least squares. $P<0.05$ was considered significant. ${ }^{17}$ In this paper changes are only referred to if they are significant.

\section{RESULTS}

Throughout these experiments we found no significant changes in cardiac output or pulmonary artery pressure. Since these variables did not change we have equated decreased perfusion to hypoxic lung with an increase in HPV. The percentage of lung made hypoxic was $32 \pm 2$ per cent of total, measured by ventilation.

\section{$\triangle$ VENTILATION GROUP}

In Figure 2 we plot the $\mathrm{Pa}_{\mathrm{CO}_{2}}$ at which nitrogen was introduced into one lung against the resulting decreased perfusion to that hypoxic lung (or HPV). Each point represents one dog. An increasing $\mathrm{Pa}_{\mathrm{CO}_{2}}$ increases $\mathrm{HPV}$. Up to a $\mathrm{Pa}_{\mathrm{CO}_{2}}$ of

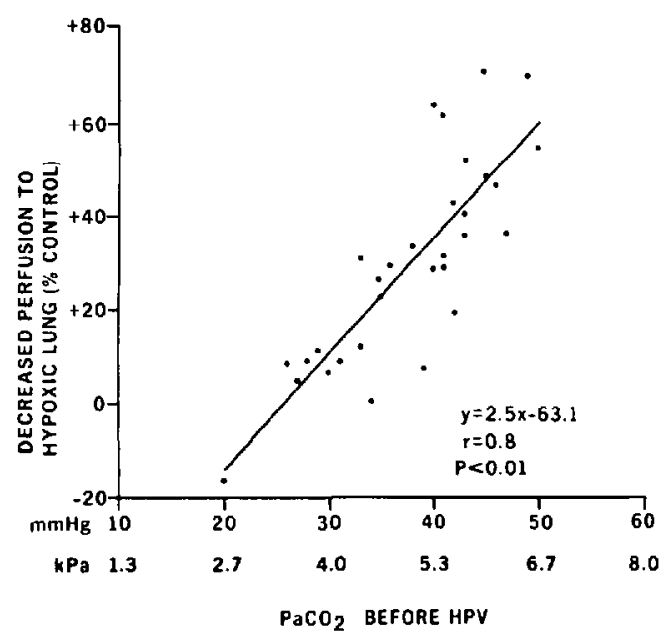

Figure $2 \mathrm{~Pa}_{\mathrm{CO}_{2}}$ before ventilating one lung area with nitrogen (before HPV) is plotted against the decreased perfusion to the hypoxic lung ventilated with nitrogen (HPV). The change in perfusion created by nitrogen ventilation is expressed as a percentage of the control value to normalize the data for hypoxic lung segment size.
$6.7 \mathrm{kPa}(50 \mathrm{~mm} \mathrm{Hg}) \mathrm{HPV}$ is enhanced. $\mathrm{At} \mathrm{a} \mathrm{Pa}_{\mathrm{CO}_{2}}$ of $3.3 \mathrm{kPa}(25 \mathrm{~mm} \mathrm{Hg}) \mathrm{HPV}$ is abolished.

The same results are found if arterial or venous $\mathrm{pH}$ are plotted against the decreased perfusion created by hypoxia (HPV[\% CONT.] $=-190$ $\mathrm{pHa}+1500, \mathrm{r}=-0.7, \mathrm{p}<0.01)$. We can make no comment about the effects of metabolic alterations in $\mathrm{pH}$, since $\mathrm{pH}$ was only altered by changing $\mathrm{Pa}_{\mathrm{CO}_{2}}$.

After $H P V$ was in place we altered ventilation and $\mathrm{Pa}_{\mathrm{CO}_{2}}$, and followed shifts in perfusion between hypoxic and hyperoxic lung areas (Figure 3). A plot similar to Figure 2 is obtained. At $\mathrm{Pa}_{\mathrm{CO}_{2}}$ values above $7.3 \mathrm{kPa}(55 \mathrm{~mm} \mathrm{Hg})$ there still seems to be no plateauing of the effect of $\mathrm{Pa}_{\mathrm{CO}_{2}}$ on HPV. There is more scatter here and the regression line is not as steep. HPV is not abolished until $\mathrm{Pa}_{\mathrm{CO}_{2}}$ values of $2 \mathrm{kPa}(15 \mathrm{~mm} \mathrm{Hg}$ ).

A low $\mathrm{PaCO}_{2}$ increased perfusion to the hypoxic lung (Figures 2 and 3 ). The greater the perfusion to the hypoxic lung, the lower the $\mathrm{Pa}_{0_{2}}\left(\Delta \mathrm{Pa}_{\mathrm{O}_{2}}=\right.$ $-10.9 \Delta$ perfusion to hypoxic lung $+4.2, \mathrm{r}=$ $-0.8, \mathrm{p}<0.01$ ). As $\mathrm{Pa}_{\mathrm{CO}_{2}}$ increased by decreasing ventilation, $\mathrm{Pa}_{\mathrm{O}_{2}}$ increased (Figure 4). When ventilation was increased and $\mathrm{Pa}_{\mathrm{CO}_{2}}$ reduced, HPV was reduced (Figures 2 and 3 ), perfusion shifted to hypoxic lung, and $\mathrm{Pa}_{\mathrm{O}_{2}}$ fell (Figure 4).

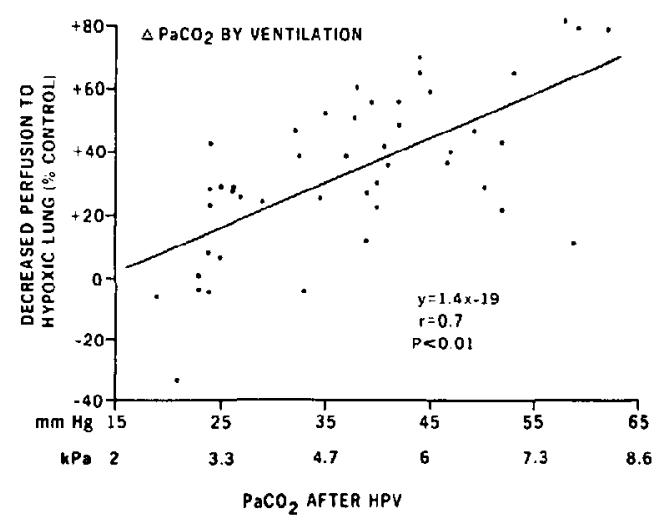

Figure 3 While the smaller lung segment was ventilated continuously with nitrogen and the other with 100 per cent oxygen, $\mathrm{Pa}_{\mathrm{CO}_{2}}$ was altered by changing ventilation. These changes in $\mathrm{Pa}_{\mathrm{CO}_{2}}$ occurred after $\mathrm{HPV}$ was present. The new $\mathrm{Pa}_{\mathrm{CO}_{2}}\left(\mathrm{~Pa}_{\mathrm{CO}_{2}}\right.$ after HPV) is plotted on the $x$ axis. The $y$ axis represents HPV and is the change in perfusion to the hypoxic lung from the oxygenated control state to the nitrogen ventilated new $\mathrm{Pa}_{\mathrm{CO}_{2}}$ state expressed as a percentage of the oxygenated control perfusion. The combination of nitrogen ventilated lung and the new $\mathrm{Paco}_{\mathrm{C}}$ level almost always decreased perfusion to the hypoxic lung (increased HPV) since most values are above the 0 level. When perfusion to the hypoxic lung increased (five times) $\mathrm{Pa}_{\mathrm{CO}_{2}}$ was always at low levels. 


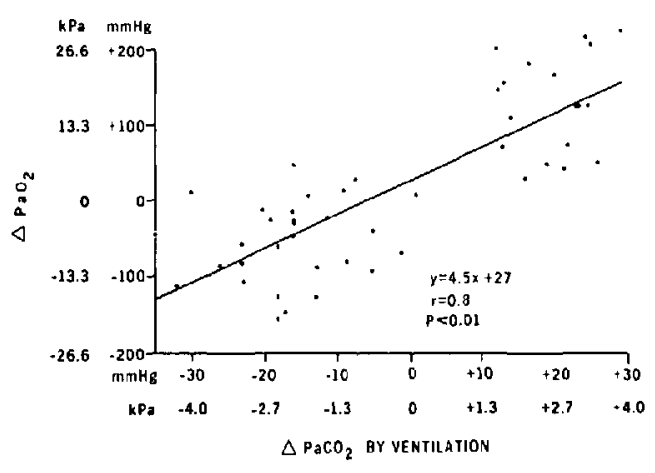

Figure 4 The changes in $\mathrm{Pa}_{\mathrm{co}}$ created by ventilation changes are plotted against the resulting changes in $\mathrm{Pa}_{\mathrm{O}_{2}}$ while the smaller lung segment was ventilated continuously with nitrogen and the other with 100 per cent oxygen. Although there would appear to be two groups of data, the same dogs appear in both groups, and the grouping results from the alternate raising and lowering of $\mathrm{Pa}_{\mathrm{CO}_{2}}$.

Data from Figures 2, 3 and 4 are all from the same dogs.

To examine whether these changes in $\mathrm{Pa}_{\mathrm{O}_{2}}$ achieved by altering $\mathrm{Pa}_{\mathrm{CO}_{2}}$ could have been influenced by ventilation per se rather than $\mathrm{Pa}_{\mathrm{CO}_{2}}$ we held ventilation constant in the inspired carbon dioxide group while $\mathrm{Pa}_{\mathrm{CO}_{2}}$ was altered by changing the inspired carbon dioxide.

\section{INSPIREd CaRboN DIOXIDE GRoup}

The same sequence was followed in every dog in this group, and is presented in Table I. Initially (measurement \#1) both lungs were hyperventilated with 100 per cent oxygen to an arterial $\mathrm{Pa}_{\mathrm{CO}_{2}}$ of $2.9 \mathrm{kPa}(22 \mathrm{~mm} \mathrm{Hg})$ to remove HPV. Carbon dioxide (5-9 per cent) was then introduced into the larger lung area that was to remain oxygenated throughout the experiment, until $\mathrm{Pa}_{\mathrm{CO}_{2}}$ was just above $5.3 \mathrm{kPa}(40 \mathrm{~mm} \mathrm{Hg}$ ) (measurement \#2). This resulted in a small but significant shift in perfusion towards the lung receiving inspired carbon dioxide. Nitrogen was then introduced into the other smaller lung area (measurement \#3, Table I) without altering the inspired carbon dioxide concentration. HPV occurred, as there was an 18 per cent shift in perfusion away from the nitrogen lung. This shift in perfusion away from hypoxic lung increased dead space, lowered the $\mathrm{PET}_{\mathrm{CO}_{2}}$ in that lung ( 3.7 to $3.1 \mathrm{kPa}$ ), and since the perfusion was shifted to the inspired carbon dioxide lung, $\mathrm{Pa}_{\mathrm{co}}$ rose (5.7 to $6.4 \mathrm{kPa}$ ). These changes resulted in a $\mathrm{Pa}_{\mathrm{O}_{2}}$ of $9.6 \mathrm{kPa}(72 \mathrm{~mm} \mathrm{Hg}$ ).

Over the next three measurements (\#4, 5 and 6) carbon dioxide was added, removed, and added again to the hypoxic lung. As both $\mathrm{Pa}_{\mathrm{CO}_{2}}$ and hypoxic lung $\mathrm{PET}_{\mathrm{CO}_{2}}$ increased, $\mathrm{HPV}$ was increased and $\mathrm{Pa}_{2}$ increased. When $\mathrm{PCO}_{2}$ fell, HPV was reduced.

Measurement \# 7 was taken when inspired carbon dioxide was removed from the oxygenated lung and left in the hypoxic lung. Since the hypoxic lung area was the smaller area, $\mathrm{Pa}_{\mathrm{CO}_{2}}$ fell to $4.7 \mathrm{kPa}(35 \mathrm{~mm} \mathrm{Hg})$ while hypoxic lung $\mathrm{PET}_{\mathrm{CO}_{2}}$ was maintained at $5.7 \mathrm{kPa}$ (43 mm Hg). In spite of the reduced $\mathrm{Pa}_{\mathrm{CO}_{2}}$, HPV and $\mathrm{Pa}_{2}$ did not significantly change.

With no inspired carbon dioxide in either lung (measurement \#8) $\mathrm{Pa}_{\mathrm{CO}_{2}}$ returned to $2.9 \mathrm{kPa}(22$ $\mathrm{mm} \mathrm{Hg}$ ), HPV was reduced, and $\mathrm{Pa}_{\mathrm{O}_{2}}$ fell to 9.4 $\mathrm{kPa}(71 \mathrm{~mm} \mathrm{Hg}$ ). When carbon dioxide was added to both lung areas again (measurement \#9) HPV was enhanced and $\mathrm{Pa}_{\mathrm{O}_{2}}$ rose to $15.6 \mathrm{kPa}(117 \mathrm{~mm}$ $\mathrm{Hg}$ ).

A comparison of measurements \#7 and \#9 again indicates that when $\mathrm{PET}_{\mathrm{CO}_{2}}$ in the hypoxic lung is held constant but $\mathrm{Pa}_{\mathrm{CO}}$ altered by changing inspired carbon dioxide in the oxygenated lung, HPV and $\mathrm{Pa}_{\mathrm{O}_{2}}$ do not change.

A comparison of measurements \#4 and \#9 indicates $\mathrm{HPV}$ and $\mathrm{Pa}_{\mathrm{O}_{2}}$ are increased with repeated applications of the same amount of carbon dioxide.

There were no significant changes in $\dot{Q}$ or PिA at any time during this experiment (lower portion, Table I).

Since hypoxic lung alveolar carbon dioxide seems important (measurement \#7, Table I), we plot the changes in $\mathrm{PET}_{\mathrm{CO}_{2}}$ in the hypoxic lung created either by changing inspired carbon dioxide or ventilation against the shift in perfusion to the hypoxic lung (Figure 5). The two regression

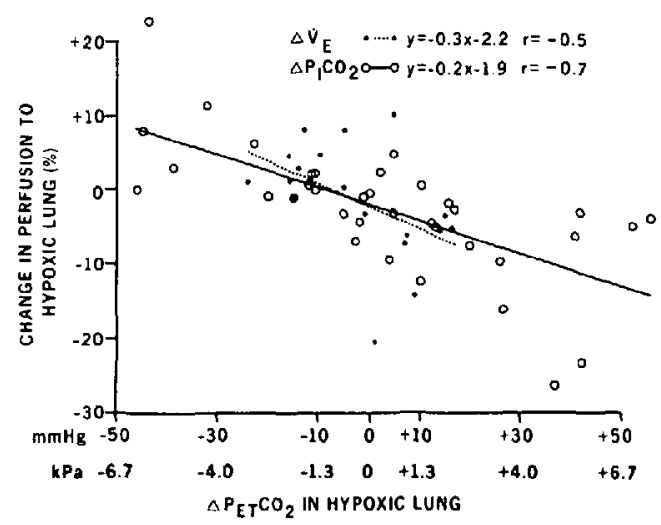

Figure 5 The change in end tidal $\mathrm{PCO}_{2}\left(\mathrm{PET}_{\mathrm{CO}_{2}}\right)$ from the hypoxic lung, created either by changing ventilation $(\Delta \dot{\mathrm{V}} E)$ or by changing inspired $\mathrm{PCO}_{2}$ ( $\left.\mathrm{PI}_{\mathrm{CO}_{2}}\right)$ is plotted against the resulting change in perfusion to the hypoxic lung. 


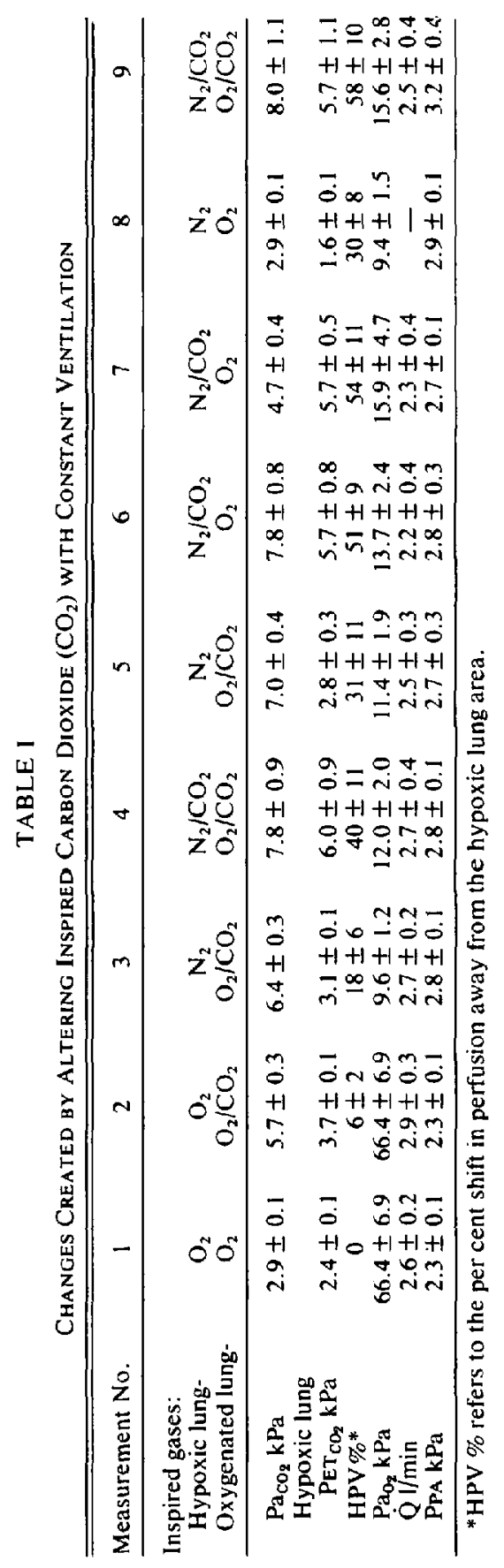


lines are not different and indicate that as hypoxic lung $\mathrm{PET}_{\mathrm{CO}_{2}}$ increases, $\mathrm{HPV}$ is enhanced.

\section{Discussion}

Our results indicate that $\mathrm{PCO}_{2}$ affects $\mathrm{HPV}$ by determining the maximum HPV that can be achieved, or by modifying existing HPV. By enhancing HPV a high $\mathrm{PCO}_{2}$ may improve oxygenation. A low $\mathrm{PCO}_{2}$ may reduce $\mathrm{HPV}$, and therefore oxygenation.

To accept these results, the experimental model used must be examined. The vasoconstrictor response to hypoxia varies in potency from one species to another. At a $\mathrm{Pa}_{\mathrm{CO}_{2}}$ of $5.3 \mathrm{kPa}(40$ $\mathrm{mm} \mathrm{Hg}$ ) induction of hypoxia decreased perfusion to hypoxic lung by 40 per cent (Figure 2). This order of magnitude correlates well with previously reported studies showing reduction of perfusion to hypoxic lung performed on isolated lungs ( 53 per cent), " open chest dogs ( $40-56$ per cent) ${ }^{18}$ and humans (27-62 per cent). ${ }^{9}$

The lung separation technique, using a Carlen's double lumen tube, results in a variable amount of separation (hypoxic lung as percentage of total, mean $32 \pm 2$ per cent, measured by ventilation). Since there were no significant changes in $\mathrm{P} \overline{\mathrm{PA}}$ or $\dot{\mathrm{Q}}$ during these experiments, the small variability (S.E. 2 per cent) of lung separation was not critical. ${ }^{19}$ However, the lung separation must remain constant throughout the experiment. We were assured of constancy because of the care taken in sealing the cuff, checking the $\mathrm{PI}_{\mathrm{O}_{2}}$ to each lung area, and finally discarding any results that indicated the ratio of ventilation to the two lung areas was changing. The advantage of the technique is that a thoracotomy involving surgery on airways and their neurovascular bundles is not required, and all hypoxic lung area is brought together so that measurements of gas exchange and perfusion can be made.

The ${ }^{133} \mathrm{Xe}$ technique used to measure perfusion requires perfect separation between two lung areas, could be influenced by changes in ventilation and does not give absolute, but only proportional, flow. The first two problems were dealt with by the checks on lung separation listed above. The third problem did not apply since, for this study, we only needed proportional flow.

Pure nitrogen ventilation of the hypoxic lung is different than hypoventilation. Oxygen will be removed from pulmonary arterial blood in the lung ventilated with nitrogen, resulting in a decrease in $\mathrm{Pa}_{\mathbf{O}_{2}}$. Oxygen removal is a factor common to both low and high $\mathrm{Pco}_{2}$ phases of the experiment and therefore should not be a problem. Nitrogen ventilation lowers the alveolar carbon dioxide in the hypoxic lung as perfusion is reduced because of HPV. This is different than a low V/Q region where $\mathrm{PET}_{\mathrm{CO}_{2}}$ may be increased. These experiments began with $\mathrm{PET}_{\mathrm{CO}_{2}}$ from both lung areas not significantly different. Once nitrogen was introduced. $\mathrm{PET}_{\mathrm{CO}_{2}}$ from the hypoxic lung was reduced. Certainly this must influence the results, for measurement \#7 in Table 1 indicates that alveolar $\mathrm{PCO}_{2}$ is important in determining how much HPV is present when alveolar and arterial $\mathrm{PCO}_{2}$ are changed in opposite directions. However, Figure 6 also indicates there are no significant differences between our results whether the $\mathrm{PCO}_{2}$ is altered by ventilation or by changing inspired carbon dioxide levels. There are also no differences whether $\mathrm{PET}_{\mathrm{CO}_{2}}$ or $\mathrm{Pa}_{\mathrm{CO}_{2}}$ are plotted against HPV (Figure 6). This consistency in our findings (Figure 6) indicates that arterial and alveolar $\mathrm{PCO}_{2}$ influence each other. However alveolar carbon dioxide exerts the main control over HPV (Table 1).

We examined the possibility that the effects of $\mathrm{PCO}_{2}$ on HPV are different before and after HPV is induced. A comparison of the slopes of Figures 2 and 3 is suggestive, but they are not significantly different.

Another factor which could influence HPV is pressure in the pulmonary vascular bed. ${ }^{11,19}$ Pulmonary artery pressures were not significantly altered by any of the manoeuvres undertaken.

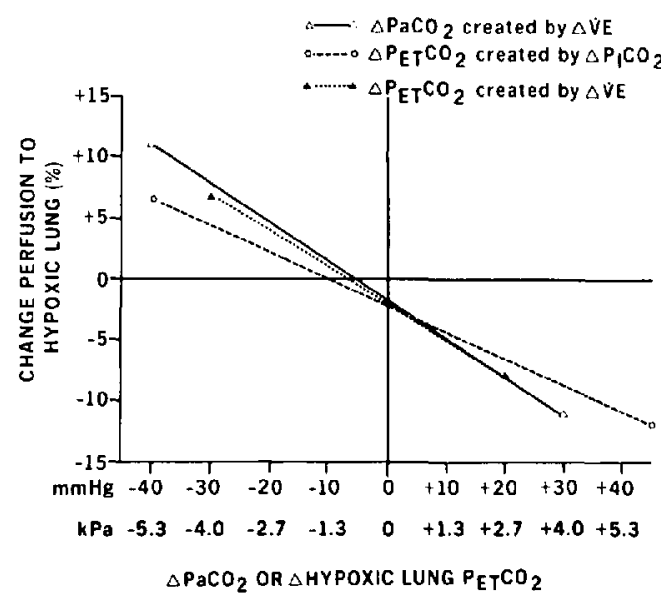

FIgURE 6 The changes in ( $\Delta$ ) $\mathrm{Pa}_{\mathrm{CO}_{2}}$ or hypoxic lung $\mathrm{PET}_{\mathrm{CO}_{2}}$ created by altering ventilation $\left(\Delta \cdot \dot{V}_{E}\right)$ or inspired carbon dioxide $\left(\Delta \mathrm{PI}_{\mathrm{CO}_{2}}\right)$ are plotted against the change in perfusion to the hypoxic lung. There are no significant differences between the regression lines. 
Cardiac output was not significantly changed despite large swings in $\mathrm{PCO}_{2}$. This could be accounted for by the variability of response to changes in $\mathrm{PCO}_{2}$ between dogs. Since neither pulmonary artery pressure nor cardiac output changed significantly with changing $\mathrm{PCO}_{2}$, alterations in HPV must have been created by $\mathrm{PCO}_{2}$ itself.

We found a small but significant six per cent shift in perfusion to the lung area with increased inspired carbon dioxide when both lungs were oxygenated (measurement \#2, Table 1). Whether this resulted from vasoconstriction in the noncarbon dioxide lung, or vasodilation in the carbon dioxide lung is speculative.

HPV and $\dot{P a}_{0_{2}}$ were always at their highest at the end of the day, sometimes at lower $\mathrm{PCO}_{2}$ levels than seen previously (see Table I). This finding might be explained by a potentiation of $\mathrm{HPV}$ by repeated changes in $\mathrm{PCO}_{2}$. Pirlo and Benumof ${ }^{20}$ have found HPV enhanced by repeated intermittent hypoxic challenges. The first hypoxic challenge only reduced hypoxic lung perfusion by $31.8 \pm 5.9$ per cent, while each successive hypoxic challenge increased the perfusion shift away from the hypoxic lung until a plateau perfusion shift of 59 per cent was reached at the fifth to eighth hypoxic challenges. Our findings and those of Pirlo and Benumof ${ }^{20}$ might indicate that HPV is mediated through an induceable mechanism.

Factors other than HPV changes might have contributed to the change in $\mathrm{Pa}_{\mathrm{O}_{2}}$. For example, changes in $\mathrm{Pa}_{\mathrm{CO}_{2}}$ may alter $\dot{\mathrm{Q}}$, shift the oxyhaemoglobin curve, and alter R. These changes, together with HPV changes, may contribute to the alterations in $\mathrm{Pa}_{\mathrm{O}_{2}}$. Measurement \#7 in Table I makes this unlikely. $\mathrm{Pa}_{\mathrm{CO}_{2}}$ has fallen, but because hypoxic lung alveolar carbon dioxide is maintained by inspired carbon dioxide, HPV, and $\mathrm{Pa}_{\mathrm{O}_{2}}$ are unchanged.

In order to maintain adequate oxygenation for dog survival it was necessary to ventilate the larger lung area with 100 per cent oxygen. This may influence the results. The effect of $\mathrm{PCO}_{2}$ on the oxyhaemoglobin dissociation curve will not change oxygen saturation at very high $\mathrm{PO}_{2}$ levels. At lower $\mathrm{PO}_{2}$ levels, on a steeper portion of the oxyhaemoglobin dissociation curve, reducing $\mathrm{PCO}_{2}$ may increase oxyhaemoglobin saturation from the oxygenated lung because of a leftward shift in the oxyhaemoglobin dissociation curve. This might partially compensate for the reduced $\mathrm{HPV}$ associated with the low $\mathrm{PCO}_{2}$. However, with an $\mathrm{FI}_{\mathrm{O}_{2}}$ of 0.21 a well ventilated alveolus will have a $\mathrm{PO}_{2}$ above $13.3 \mathrm{kPa}(100 \mathrm{~mm} \mathrm{Hg})$ and haemoglobin would be almost fully saturated at $\mathrm{PCO}_{2}$ levels of $2.66 \mathrm{kPa}(20 \mathrm{~mm} \mathrm{Hg})$. Therefore at $\mathrm{FI}_{\mathrm{O}_{2}} \mathrm{O} .21$ in the non-hypoxic lung the magnitude of our $\mathrm{Pa}_{\mathrm{O}_{2}}$ changes should not be reduced.

The alveolar gas equation states $\mathrm{P}_{\mathrm{A}_{\mathrm{O}_{2}}}$ will decrease with a high $\mathrm{PA}_{\mathrm{CO}_{2}}$. Our findings include this factor and indicate that in spite of the alveolar gas equation, HPV enhancement with a high $\mathrm{Pa}_{\mathrm{CO}_{2}}$ increases $\mathrm{Pa}_{\mathrm{O}_{2}}$. Measurements 7 and 9 in Table I indicate how important $\mathrm{HPV}$ is. $\mathrm{Pa}_{\mathrm{CO}_{2}}$ has increased from $4.7 \mathrm{kPa}$ to $8 \mathrm{kPa}(35$ to $60 \mathrm{~mm} \mathrm{Hg}$ ) and should have reduced $\mathrm{Pa}_{\mathrm{O}_{2}}$ by a similar amount, but $\mathrm{HPV}$ and $\mathrm{Pa}_{\mathrm{O}_{2}}$ did not change significantly.

These findings together with the fact that there is no significant change in $\dot{Q}$, indicate that the changes in $\mathrm{Pa}_{\mathrm{O}_{2}}$ in this experiment were the result of changes in HPV created by hypoxic lung PeT $_{\mathrm{CO}_{2}}$ alterations.

In patients undergoing anaesthesia, three factors (other than ancillary drugs) might influence HPV. These are: inhaled anaesthetics; ${ }^{8-10,4-6}$ intravascular pulmonary pressures; ${ }^{11,19}$ and carbon dioxide levels. Intravenous anaesthetics do not seem as important ${ }^{8-10}$ While we have no comparative data, a literature search suggests that $\mathrm{PCO}_{2}$ may be the most important, over inhaled anaesthetic level and pulmonary vascular pressures, in influencing HPV. For example, Benumof and Wahrenbrock " decreased HPV in dogs by 30 per cent by lowering $\mathrm{Pa}_{\mathrm{CO}_{2}}$ from $5.3 \mathrm{kPa}$ to $2.7 \mathrm{kPa}$ (40 to $20 \mathrm{~mm} \mathrm{Hg}$ ). At a $\mathrm{Pa}_{\mathrm{CO}_{2}}$ of $5.3 \mathrm{kPa}(40$ $\mathrm{mm} \mathrm{Hg}$ ) the same decrease in HPV did not occur until left atrial pressures were elevated to $2.9 \mathrm{kPa}$ $(22 \mathrm{~mm} \mathrm{Hg}$ ). They also found that fluroxene would not achieve this reduction in HPV until levels greater than 2 MAC. Isoflurane reduced HPV by 30 per cent at 3 MAC while nitrous oxide could not achieve this reduction and halothane did not impede HPV. ${ }^{8}$ Sykes et al. found similar data with nitrous oxide. ${ }^{6}$ Sykes et al. found that one per cent trichlorethylene reduced HPV by 24 per cent, ${ }^{4}$ and five per cent diethyl ether reduced HPV by 28 per cent. ${ }^{5}$ Bjertnaes ${ }^{9}$ found that halothane decreased HPV by 20 per cent while diethyl ether decreased HPV by 30 per cent. These papers and our results suggest it is $\mathrm{PCO}_{2}$ that must be critically controlled if HPV is to be enhanced under anaesthesia or in an intensive care unit setting.

The importance of these findings to the anaesthetist is found in Figure 4. An increase of $\mathrm{Pa}_{\mathrm{CO}_{2}}$ increased $\mathrm{Pa}_{\mathrm{O}_{2}}$ in these dogs with HPV present. This finding correlates well with the increased 
HPV or perfusion shifts away from hypoxic lung found at a high $\mathrm{Pa}_{\mathrm{CO}}$ (Figures 2 and 3). We must emphasize that this does not mean that a higher $\mathrm{Pa}_{\mathrm{CO}_{2}}$ will always increase $\mathrm{Pa}_{\mathrm{O}_{2}}$. Only when hypoxic pulmonary vasoconstriction exists and can respond to $\mathrm{PCO}_{2}$, will increasing $\mathrm{PaCO}_{2}$ increase $\mathrm{Pa}_{\mathrm{O}_{2}}$. This experiment in dogs has allowed us to dissect out an effect of $\mathrm{PCO}_{2}$ on both HPV and $\mathrm{Pa}_{\mathrm{CO}_{2}}$ in a way that the complex clinical situation does not permit. One must take care in applying these results to patients. For example, HPV may not exist in some patients, or may not respond to $\mathrm{Pa}_{\mathrm{CO}_{2}}$ changes if $\mathrm{PET}_{\mathrm{CO}_{2}}$ in the hypoxic lung is not changing. $\mathrm{PCO}_{2}$ also has many other effects than those on HPV, which may be more important in determining the optimum $\mathrm{PCO}_{2}$ for a patient.

\section{ACKNOWLEDGEMENTS}

We thank G. Caskennette and E. Janssen for their valuable technical assistance and $P$. Slusarenko for typing the manuscript. We gratefully acknowledge the valuable discussions with Dr. R.J. Byrick and Dr. J. Obdrzalek. This project was supported by the York-Toronto Lung Association and the Medical Research Council of Canada.

\section{REFERENCES}

1. Fishman, A.P. Respiratory gases in the regulation of the pulmonary circulation. Physiol. Rev. 214 (1961).

2. Hales, C.A., Ahluwalia, B. \& Kazemi, H. Strength of pulmonary vascular response to regional alveolar hypoxia. J. Appl. Physiol. 38: 1083 (1975).

3. Hughes, J.M.B. Lung gas tensions and active regulation of ventilation/perfusion ratios in health and disease. Br. J. Dis. Chest 69: 153 (1975).

4. Sykes, M.K., ARNot, R.N., Jastrzebski, J., Gibes, J.M., Obdrzalek, J. \& Hurtig, J.B. Reduction of hypoxic pulmonary vasoconstriction during trichorethylene anaesthesia. J. Appl. Physiol. 39: 103 (1975).

5. Sykes, M.K., Hurtig, J.B., Tait, A.R. \& ChakRABARTI, M.K. Reduction of hypoxic pulmonary vasoconstriction during diethyl ether anaesthesia in the dog. Br. J. Anaes. 49: 293 (1977).
6. Sykes, M.K., Hurtig, J.B., Tait, A.R. \& ChakRABARTI, M.K. Reduction of hypoxic pulmonary vasoconstriction in the dog during administration of nitrous oxide. Br. J. Anaes. 49: 301 (1977).

7. Sykes, M.K., Loh, L.. SeEd, R.F., Kafer, E.R. \& ChakrabarTl, M.K. The effect of inhalational anaesthesia on hypoxic pulmonary vasoconstriction and pulmonary vascular resistance in the perfused lungs of the dog and cat. $\mathrm{Br}$. J. Anaes. 44 : 776 (1972)

8. Benumof, J.L. \& Wahrenbrock, E.A. The local effect of anaesthetics on regional hypoxic pulmonary vasoconstriction. Anesthesiology 43: 525 (1975).

9. Bjertnaes, L.J. Hypoxia-induced pulmonary vasoconstriction in man: Inhibition due to diethyl ether and halothane anesthesia. Acta. Anaesth. Scand. 22: 570 (1978).

10. Bjertnaes, L.J. Hypoxia-induced vasoconstriction in isolated perfused lungs exposed to injectable or inhalation anesthetics. Acta. Anaesth. Scand. 21: 133 (1977).

11. Benumof, J.L. \& Wahrenbrock, E.A. Blunted hypoxic pulmonary vasoconstriction by increased vascular pressures. J. Appl. Physiol. 38: 846 (1975).

12. Benumof, J.L., Mathers, J.M. \& WahrenBROCK, E.A. Cyclic hypoxic pulmonary vasoconstriction induced by concomitant carbon dioxide changes. J. Appl. Physiol. 41: 466 (1976).

13. LLOYD, T.C. JR. Influence of blood pH on hypoxic pulmonary vasoconstriction. J. Appl. Physiol. 21: 358 (1966)

14. SYKES, M.K., HILl, A.E.G. \& LoH, L. Evaluation of a new method for the continuous measurement of the distribution of blood flow between two lungs. Br. J. Anaes. 49: 292 (1977).

15. Arborelius, M. JR. ${ }^{35} \mathrm{Kr}$ in the study of pulmonary circulation during bronchospirometry. Scand. J. Clin. Invest. 17: 253 (1965).

16. Noble, W.H. \& KaY, J.C. Cardiac catheterization in dogs. Can. Anacsth. Soc. J. 2I: 616 (1974).

17. Snedecor, G.W. \& Cochrane, W.G. Statistical Methods. 6th edition, IOWA State University Press, Iowa City, 1967.

18. Barer, G.R., Howard, P. \& Shaw, J.W. Stimulus-response curves for the pulmonary vascular bed to hypoxia and hypercapnia. J. Physiol. 211: 139 (1970)

19. Marshall, B.E. \& Marshall, C. Continuity of response to hypoxic pulmonary vasoconstriction. J. Appl. Physiol 49: 189 (1980).

20. Pirlo, A. \& Benumof, J.L. Hypoxic pulmonary vasoconstriction and intermittent hypoxia. Anesthesiology suppl. 53 : 5380 (1980) Abstract.

\section{RÉSUMÉ}

Les zones pulmonaires dont le rapport V/Q est bas produisent de l'hypoxémie. La baisse de concentration de l'oxygène alvéolaire par contre entraine de la vasoconstriction hypoxique locale, ce qui a pour effet de diminuer la perfusion, améliorer le rapport $V / Q$ et ainsi diminuer la tendance à l'hypoxémie. En modifiant la $\mathrm{PCO}_{2}$, on peut altérer la vasoconstriction hypoxique pulmonaire. Nous avons examiné cette relation sur des chiens anesthésiés en utilisant une cloison trachéale qui séparait un poumon rendu hypoxique par ventilation à l'azote, d'un poumon oxygéné avec 100 pour cent d'oxygène. La perfusion relative a été évaluée par la mesure du ${ }^{133} \mathrm{Xe}$ expiré par chaque poumon après injection intraveineuse. 
Lorsqu'on a modifié la $\mathrm{Pa}_{\mathrm{CO}_{2}}$ en changeant la ventilation, nous avons trouvé qu'une augmentation de la $\mathrm{Pa}_{\mathrm{CO}_{2}}$ augmentait la vasoconstriction pulmonaire hypoxique et ainsi la $\mathrm{Pa}_{\mathrm{O}_{2}}$. A une $\mathrm{Pa}_{\mathrm{CO}_{2}}$ de $3.3 \mathrm{kPa}$, la vasoconstriction hypoxique pulmonaire a été abolie et la $\mathrm{Pa}_{\mathrm{O}_{2}}$ s'est abaissée. Nous avons modifié aussi la $\mathrm{Pa}_{\mathrm{CO}_{2}}$ en changeant la $\mathrm{Pl}_{\mathrm{CO}_{2}}$ pour un ou les deux poumons alors que la ventilation demeurait constante pendant l'expérience: encore là, lorsque la $\mathrm{Pa}_{\mathrm{CO}_{2}}$ a augmenté, la vasoconstriction hypoxique pulmonaire et la $\mathrm{Pa}_{\mathrm{O}_{2}}$ ont aussi augmenté. Lorsque la $\mathrm{Pa}_{\mathrm{CO}_{2}}$ s'est abaissée et que la mesure du $\mathrm{CO}_{2}$ du poumon hypoxique en fin d'expiration ( $\mathrm{PET}_{\mathrm{CO}_{2}}$ ) est demeuré élevée (en maintenant la $\mathrm{PI}_{\mathrm{CO}_{2}}$ dans le poumon hypoxique et en retirant le $\mathrm{CO}_{2}$ du poumon oxygéné) la vasoconstriction hypoxique a été maintenue. On peut en conclure que c'est la concentration alvéolaire de $\mathrm{CO}_{2}$ dans le poumon hypoxique qui permet de modifier la vasoconstriction hypoxique.

Nous avons conclu que sur ce modèle une PET $\mathrm{PO}_{2}$ basse $(3.3 \mathrm{kPa})$ va diminuer la vasoconstriction pulmonaire hypoxique sur le poumon hypoxique et va ainsi augmenter la gravité de l'hypoxémie. Ceci peut avoir de l'importance chez le malade sous anesthésie et aux soins intensifs où une augmentation de la $\mathrm{PET}_{\mathrm{CO}_{2}}$ du poumon hypoxique permettra d'obtenir une $\mathrm{Pa}_{\mathrm{O}_{2}}$ plus élevée. L'influence de la $\mathrm{PET}_{\mathrm{CO}_{2}}$ sur la $\mathrm{Pa}_{\mathrm{CO}}$ peut être modifiée par d'autres facteurs variables mais quand il existe des zones hypoventilées ou hypoxiques, l'augmentation de la $\mathrm{PET}_{\mathrm{CO}_{2}}$ peut augmenter la vasoconstriction hypoxique et par le fait mème augmenter la $\mathrm{Pa}_{\mathrm{O}_{2}}$. 